respect and interest, I submit them as they. stand to his consideration, and to that of others who may care to follow up these somewhat subtle questions.-P.S.]

\title{
REFERENCES
}

1, 2, 3. Smith, Priestley.-Brit. Jl. of Ophthal., pp. 4 and 657, 1917, p. 257, 1918.

4. Leber, I h. -Graefe-Saemisch Handb., 2nd ed., Vol. II, pt. ii.

5. Parsons, Sir J. H.- Pathology of Eye, Vol. III, p. 1041.

6. Walker, Cranston.-Brit. Med. Jl., p. 260, Feb. 18, 1922.

7. Batten, Rayner.-Proc. Roy. Soc. Med., Sect, Ophthal., p. 72, Feb., 1913.

8. v. Schultén. - Arch. f. Ophth., Vol. XXX, pt. iii, p. 1. (Brit. Jl. of Ophthal., p. 258, 1918).

9. Henderson, Thomson.-Trans. Ophthal. Soć. of U.K., Vol. XXXIV, p. 309.

10. Bailliart, P.-Annal. d'Oculist., pp. 257 and 648, 1917 (Brit. Jl. of Ophthal., p. 258, 1918).

11. Smith, Priestley. - Path. etc. of Glauc., London, p. 104, 1891.

12. Schiötz, H. J.-Arch. f. Augenheilk., Vol. LXII, p. 317.

13. Smith, Priestley.-Ophth. Rev., p. 77, 1915.

14. Koster, W.-Arch.f. Ophth., Völ. LII. p. 402.

15. Bailliart, P.-Annal. d'Oculist., p. 672, 1919.

16 Velter, E.-Arch d'Ophtal., p. 88, Feb., 1920 (Brit.Jl. of Ophthal., p. 382, 1920).

17. Duverger and Barré.-Arch. d'Ophtal., p. 71 (Brit. Jl. of Ophthal., p. 382, 1920).

18. Hill, Leonard.-Schaefer's Physiology, Xol. II, p, 147, 1900.

19. Henderson, Thomson. - Glaucoma, London, pp. 85-87, 1910.

20. Elliot, R. H. - Brit. Jl. of Ophthal.,p. 481, 1921.

21. Lang and Barrett.-Roy. Lond. Ophth. Hosp. Reps., Vol. XII, p. 60.

22. Kuemmel, R. - Arch. f. Augenheilk., Vol. IXXXVIII, p. 336, 1915.

23. de Speyr, Th.-Annal..d'Oculist., Dec., 1914.

24. Helfreich, Fr.-Arch. f. Ophth., Vol. XXVIII, pt. iii, p. 1.

25. Bailliart, P. Annal. d'Oculist., Oct.-Nov., 1918.

26. Mackenzie, Sir J.-Diseases of the Heart, London, Fig. 44, 1908.

27. Ballantyne, A. J.-Internat. Med. Cong., Lond., Sect. Ophthal., pt. ii, p. 208, 1913.

28. Bailliart, P.-Annal. d'Oculist., p. 432, April, 1922.

29. Fuchs, E. - Lehrbuch d. Augenheilk., p. 507, 1910.

30. Coats, G.-Arch. f. Ophth, Vol. LXXXVI, pt. ii, p. 341,1913 (Ophth. Rev., p. 9, 1914).

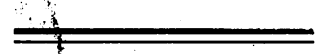

\section{THE PECTINATE LIGAMENT IN ITS RELATION TO CHRONIC GLAUCOMA \\ BY}

\author{
Lt.-Col. H. Herbert \\ HOVE, SUSSEX
}

THE greater part of this report was read at the last Ophthalmological Congress at Oxford, in recognition of Professor Arthur Thomson's well known work on the same subject.

The results are given here of a recent research upon over thirty eyes. The starting point of the investigation was the obtaining of an eye in so early a stage of chronic simple glaucoma that a rare opportunity was afforded of looking for predisposing anatomical causes of the disease, uninfluenced by the secondary effects of high tension. The plus tension began while the 
patient, aged 53 years, was in hospital, and was controlled by eserin almost from the beginning, the patient dying a few weeks later.

The most convincing results were got by deep staining with elastic tissue stains. The differentiation thus obtainable seems essential for the demonstration of the finer structure of some of the tissues.

On the whole the best results were got from a particular supply of orcein, discarded years ago because of its incompletely selective action. One of the objections to orcein has been the very variable quality of the supplies obtainable; but by working steadily with the one brand more instructive pictures have been obtained than by any other method. A 2 per cent. or 3 per cent. solution in acid alcohol (HC1 1, methylated spirit 100) has been used chiefly. 'The solution

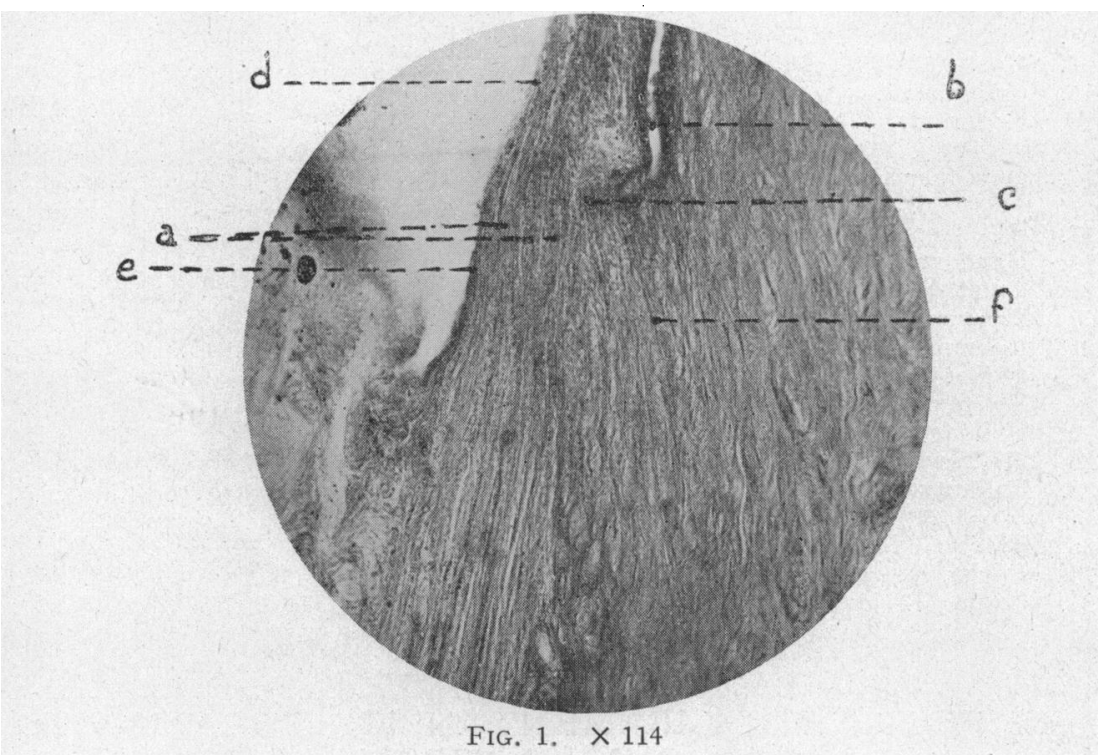

containing the celloidin sections was placed in the incubator, or heated slowly over a flame, until of syrupy consistence from evaporation, and then left covered for a couple of hours. The over-stained sections were differentiated in acid alcohol and in alcohol, used alternately till the desired effect was obtained. At one stage each ciliary muscle bundle cut in cross section is seen to be permeated by a close network of elastic tissue, but this mostly disappears if decolourization is carried far enough to show the finer structure of the pectinate ligament.

Fig. 1 is taken from the glaucomatous eye above mentioned. The structure first claiming attention is the rather dark, thick tendon (a). It is clearly the tendon of the longitudinal or meridional portion of the ciliary muscle, which is somewhat unusually well defined in this eve. Imperfect lines of division are seen between bundles alike of muscle and of tendon, separating also the tendon from the adjacent sclera (f). And the longitudinal direction of the fibres of the tendon is well shown by the elastic 
tissue stain. Otherwise the sloping line of division between muscle and tendon, though not very sharply defined, might give rise to an erroneous impression of a wide inward-projecting scleral spur or process, forming a complete break in continuity between muscle and pectinate ligament; more particularly since, as in most eyes, the structure of the scleral tissue immediately in contact with the tendon is much more like that of the tendon than is the remainder of the sclera. The two structures are doubtless adherent to one another.

Anteriorly (upwards in the photograph) the fibres of the tendon are seen to pass on without interruption into the slightly looser lamellae of the pectinate ligament. They form a very considerable portion of the width of the ligament.

If the scleral spur or process be defined as the portion of sclerotic forming the posterior boundary of the scleral groove in which Schlemm's canal (b) lies, the angle of the spur (c) is seen to the inner (left) side of the bent end of the canal, separated by a narrow clear line from the tendon. The distinction between sclera and tendon is, therefore, a little more definite at this point.

Quite the innermost trabeculae of the ligament (d), forming a loose network, faint and blurred in the photograph, are seen to be connected by a long narrow elastic band (e), lying on tendon and longitudinal muscle, and bounding the sinus of the anterior chamber with a bundle of muscle fibres seen in cross section. Actually the connection is with a large irregular mass of elastic tissue, very imperfectly stained in this section, forming the main attachment of the oblique (radial) and circular muscle bundles. The elastic band and its ligamentous trabeculae are very distinctly narrower than in most eyes. In this glaucomatous eye, therefore, all the inner more movable portion of the ciliary muscle is placed at a mechanical disadvantage with respect to any inward pull that it may exert upon the lamellae of the pectinate ligament, and, through them, on Schlemm's canal, when the muscle contracts inwards. The mechanical disadvantage consists : (1) in the slenderness of the connecting band and of the. trabeculae directly continuous with it; and (2) in the intrusion in the ligament of the broad middle section of lamellae derived from the meridional tendon, separating widely the innermost trabeculae from the outer purely scleral lamellae, which extend forward from the scleral spur; and (3) in the relatively great distance of the muscle, as a whole, behind Schlemm's canal. The angle of the anterior chamber is seen to be placed far back, in relation to the canal.

Sections of the fellow eye, considerably more advanced in chronic glaucoma, present the same features. 
The first normal filtration angle, Fig. 2, that became available for comparison under similar staining presents some remarkable contrasts with the above findings. The globe was removed for choroidal sarcoma; tension normal, patient aged 32 years.

The pectinate ligament in this eve is made up entirely of a small inner open, but fairly strong, portion (a) connected with the radial and circular muscle bundles, and a broader outer compact scleral portion (b), into which the angle of the scleral process pushes forward for some distance. There is no definite middle portion of ligament continued forwards from the rather feebly developed meridional muscle bundles (c). The latter have

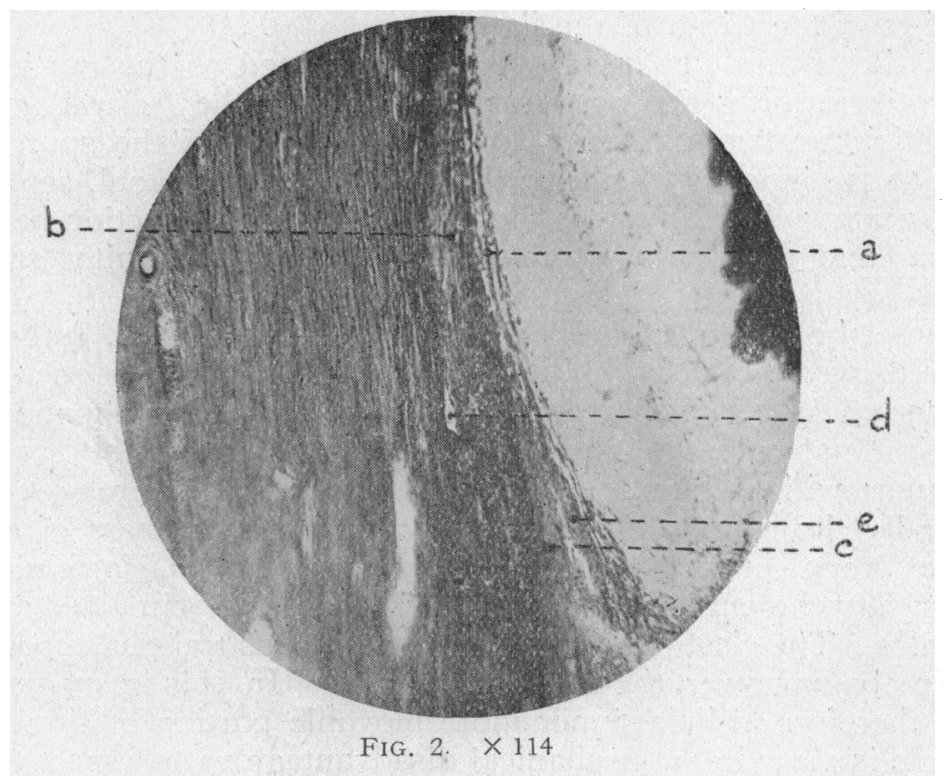

no recognizable tendon at all; they undoubtedly extend forward between the sharply defined sclera and the inner loose trabeculae a little beyond the level of the posterior end of Schlemm's canal (d).

The circular muscle fibres in this eye are much better placed for inward traction on the outer scleral portion of the ligament, and, through it, on the canal, even though the angle of the anterior chamber extends rather far back. A strand of oblique muscle fibres (e) can be seen curving forward with the elastic band connecting circular muscle and ligament.

(Schlemm's canal is closed and the scleral lamellae of the ligament are pressed closely together. But this is attributable to the 10 per cent. formalin solution used for fixation of the eye. 
The vitreous became swollen, pressing the lens and iris considerably forwards and making the globe tense.)

Fig. 3, from another eye, appears necessary to illustrate extreme inward pull on the pectinate ligament. The canal (a) is widely opened; the trabeculae are separated, and, in front of the canal (above), apparently ruptured. The traction is from cyclitic membrane, a result of old cyclitis, drawing the ciliary processes forward and inward. But the influence on the ligament and canal seem to be directly through the ciliary muscle, and may, therefore, be taken to show fairly well the maximum effect of powerful and continued contraction of the muscle. In some normal eyes the

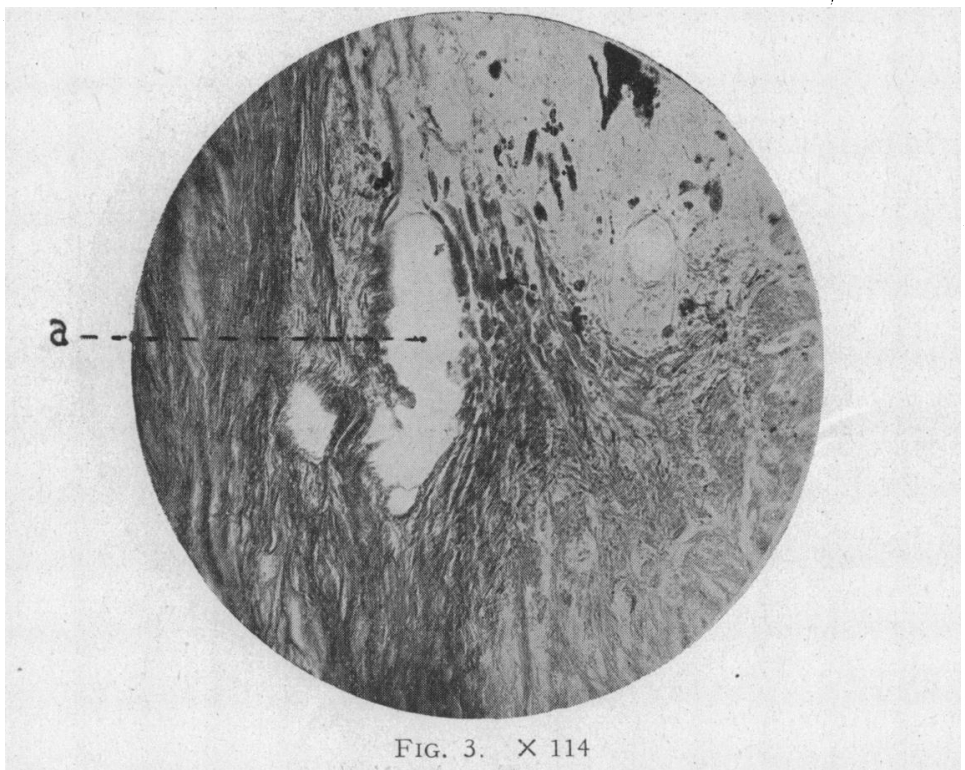

muscle is placed almost as far forward as in this eye, the angle of the chamber lying in front of the level of the posterior end of Schlemm's canal.

Fig. 4, from a patient aged 46 years, shows a condition not very unlike the above. (The blurring of the tissues is due to imperfect fixation, the elastic fibres not being cleanly cut. Such blurring, not so readily recognizable under ordinary staining, may have been partly responsible for divergent views upon the anatomy of these parts. Curiously, it appears to be limited always to these particularly highly elastic tissues, and sometimes produces a false appearance of an inwardly projecting scleral process).

The canal (a) is well opened, and all the scleral lamellae of the pectinate ligament (b) are seen to be curved inwards and slightly 
separated from one another. Arching outwards to meet these lamellae is a thick band of elastic fibres (c) from the circular and radial muscle. The outer edge of this elastic band almost meets the inner border of the arched scleral trabeculae behind the level of the middle of the canal, to form together nearly the whole of the ligament in front of the junction. Thus, here again the longitudinal muscle, though very well developed, is almost excluded from participation in the formation of the ligament; and in consequence the inner portions of the muscle can exert much more traction on the scleral trabeculae and on the canal than in the glaucomatous eye.

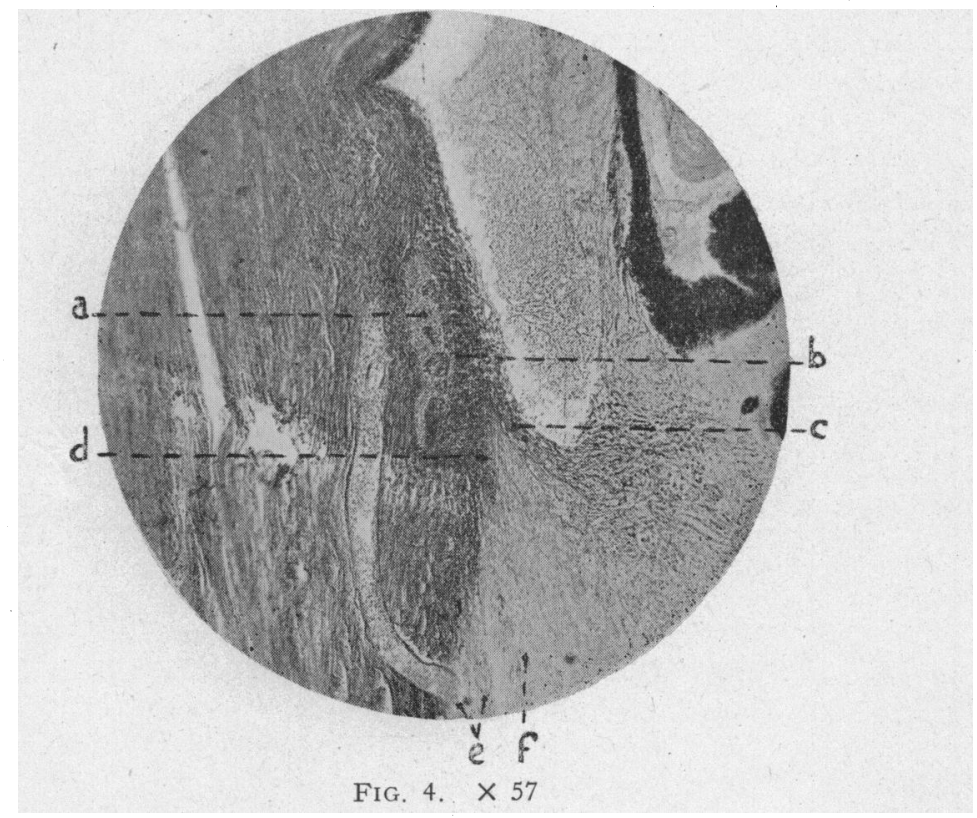

The opening of the canal and the arching inwards of the scleral lamellae in this case are due to closely packed blood cells, finding their way out of the anterior chamber after a recent injury. But there is little doubt that a very similar effect could be produced by strong inward contraction of the circular muscle, acting through the well-placed broad elastic band. Inward traction on the ligament is facilitated by the forward position of the muscle.

It may be noticed that in this eye the two outermost meridional muscle bundles (e) are inserted into (or arise from) the sclerotic, rather far back. Another fasciculus (f) runs into the dark patch of fibro-elastic tissue (d) which seems certainly to be a small strip of tendon. The tendency to fibrosis, with advancing years, appears often to be most marked in this position, next to the 
sclerotic. The formation may approximate closely to scleral tissue, sometimes containing bands of fibres cut transversely, which may, or may not, be separated from the sclera by meridional fibres continued forwards from muscle fibres. Thus, one approaches to the forward-and-inward projecting scleral spur, which may apparently be sufficiently narrow and prominent--and therefore mobile-to serve in Professor Thomson's well-known "pump action" theory. In accommodation of the eye the process, drawn backwards and inwards by the meridional muscle inserted into it, is supposed to open the ligamentous spaces and Schlemm's canal; and the subsequent recoil of the process by its own elasticity and by that of the attached ligament is expected to force fluid on from the filled canal into efferent veins. There has been no such scleral process among the eyes stained for this research. And without effective differential staining one is very apt to mistake partial tendon-formation for a true scleral spur, so that mistakes are readily made in looking through one's old sections,

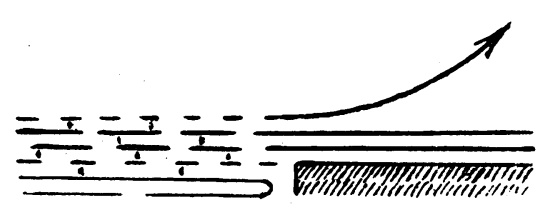

FIG. 5a.

especially among those not quite meridionally cut. But from the micro-photographs shown by Professor Thomson at Oxford, there seems to be little doubt that the above description must be accepted as applying to a definite type of eye-one, however, not very common.

The striking anatomical variations here shown and discussed appear to have escaped serious notice hitherto. They possibly include all the main types, but there are many connecting links between the extreme variations.

In the descriptions given in the text above inferences have been suggested. The contrast between the finding in the glaucomatous eye and in the almost normal eyes of Figs. 2 and 4, seems to point in a definite direction. A new "glaucoma theory" is suggested on the assumption that the normal tone of the ciliary muscle keeps up slight continuous traction on the attachments of the muscle. In Fig. 1, represented diagrammatically in Fig. 5a, a predisposition to chronic simple glaucoma may be attributed to imperfect mechanism for drainage, the imperfection being comprised in ineffective action of the circular and radial portion of the ciliary muscle on the pectinate ligament. These inner muscle 
bundles, ill-placed and ill-connected, are "crowded out" by the intrusion in the ligament of a broad median strip of lamellae directly continuous with the meridional muscle.

Fig. 5b, corresponding with Figs. 2 and 4 , presents the direct contrast to the above. Here the meridional muscle is crowded out from the ligament, and there is nothing to interfere with the traction exerted by the inner more mobile part of the muscle, opening up the inter-lamellar spaces of the ligament and the canal.

The anatomy depicted by Professor Thomson* seems particularly well adapted for drainage. The band from the inner muscle fibres sweeps past the end of the projecting spur and the meridional muscle inserted into the spur and assists in opening up the trabecular spaces and canal. Hence the importance of distinguishing between tendon and scleral process, since in Fig. 1 contraction of the meridional muscle can only have the opposite effect, impeding drainage by drawing the directly connected lamellae tightly together.

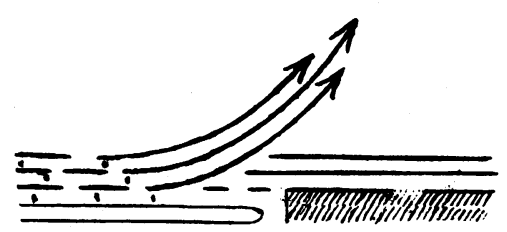

FIG. 5b.

The suggested anatomical predisposition may be regarded as partly individual, but increasing with age as a result of senile fibrosis. Also decline in tone of the muscle with advancing years may be considered to contribute slightly to the glaucomatous tendency. On the other hand, powerful contraction of the circular muscle fibres under the influence of eserin may have sufficient action on the pectinate ligament, even in eyes thus predisposed to glaucoma, to correspond with clinical experience of the influence of the medicament on the tension in chronic glaucoma, an influence varying much in different cases of the malady.

The practical question is : does the suggestion bear investigation? Is there a fairly constant and exclusive association of the anatomy of Figs. 1 and 5a with chronic glaucoma?

Investigation is far from easy. One must expect to find the predisposition in some eyes in which the disease has not yet supervened. On the other hand, some primary glaucomas must occur quite unconnected with this predisposing factor, since this

* See plate facing p. 472 of The Ophthalmoscope, Vol. IX (1911), also Elliot's Treatise. 
anatomical influence is a thing quite apart from the shallowing of the anterior chamber and closure of the filtration angle long established as primary causes of glaucoma. On this account the influence may be considerable in pure chronic simple glaucoma, and quite inconsiderable in acute glaucoma and in the type of the disease which is in the initial stages definitely periodic. That is to say, one may expect it to occur more particularly in the eyes which least often need excision, and least often, therefore, become available for pathological examination. Further, in absolute glaucoma the parts are sometimes so compressed as to afford little information regarding the original condition. And there is sometimes the difficulty, already sufficiently alluded to, of distinguishing between scleral spur and tendon.

In spite of all these sources of confusion, a very definite relationship between primary glaucoma and the particular type of ligamentous connections of Figs. 1 and 5a emerges unmistakably from examination of available old pathological material. Under the circumstances one is a little surprised at the amount of support thus forthcoming for the suggestion. Slides from the (primarily) glaucomatous eyes of over forty patients have been examined in this connection, including a few of the eyes specially stained for this work. More than half the eyes examined belonged more or less definitely to the glaucomatous type, as above defined. That is, a broad section of ligamentous lamellae served as the means of attachment of longitudinal muscle, greatly limiting the direct attachment of the middle and inner muscle bundles; and the muscle as a whole was placed rather far back. Some of the glaucomas to which the description applied were apparently acute from the beginning. On the other hand, in a search among nonglaucomatous eyes this anatomical feature has been but seldom met with.

This paper serves to show how incomplete is our knowledge of the normal anatomy of this most important part of the eye. The influence of age in particular needs precise determination. Uniform fixation and strictly meridional sectioning are essential, if mistakes are to be avoided. On account of insufficient care exercised in these respects, no comment of value can be made upon Thomson Henderson's conception of sclerosis of the pectinate ligament as a cause of glaucoma.

Thanks are due to Mr. Chesterman of Oxford for the excellent micro-photographs shown. 